\title{
O Museu Histórico da Imigração Japonesa no Brasil
}

\begin{abstract}
Shozo Motoyama
Diretor do Museu Histórico de Imigração Japonesa/SBCJAS. Doutor em História Social pela Universidade de São Paulo. Professor titular da FFLCH/USP. Presidente do Centro de Estudos Nipo-Brasileiros. Tem experiência na área de História, com ênfase em História das Ciências ${ }^{1}$. E-mail: museu@bunkyo.org.br
\end{abstract}

Resumo: As comemorações do Centenário da Imigração Japonesa no Brasil, ocorridas em junho de 2008, ofereceram um panorama completo da cultura, das artes e da tecnologia do Japão para o Brasil. Uma das associações responsáveis pela organização das festividades foi a Sociedade Brasileira de Cultura Japonesa e de Assistência Social - Bunkyo (abreviatura do nome da associação em japonês). Entre outras atividades, o Bunkyo mantém 30 Comissões temáticas focadas em variadas frentes: organização dos eventos anuais e especiais, recepção a autoridades e administração das instalações culturais, como o Museu Histórico da Imigração Japonesa, que será apresentado nesta seção.

Palavras-chave: imigração, Kasato Maru, cultura, museu, Bunkyo.
Abstract: The celebrations of the centenary of Japanese Immigration in Brazil, which occurred in June 2008, offered a complete overview of culture, arts and technology from Japan to Brazil. One of the associations responsible for organizing the festivities was the Brazilian Society of Japanese Culture and Social Welfare - Bunkyo (abbreviation of the name of the association in Japanese). Among other activities, the Bunkyo maintains $30 \mathrm{Com}$ missions thematic focus for many fronts: organization of annual and special events, the authorities receipt and administration of cultural facilities such as the Historical Museum of Japanese Immigration, which will be presented in this section.

Keywords: immigration, Kasato Maru, culture, museum, Bunkyo.

O Museu Histórico da Imigração Japonesa no Brasil foi inaugurado em 18 de junho de 1978, e idealizado como a grande realização do 70ํaniversário da imigração japonesa no Brasil. A cerimônia de abertura foi prestigiada pelo então príncipe herdeiro Akihito do Japão e pelo presidente da República Ernesto Geisel.

O objetivo da Sociedade Brasileira de Cultura Japonesa (Bunkyo-SP), responsável pela iniciativa, foi o de registrar e preservar tudo o que pudesse contar a vida dos imigrantes japoneses no Brasil, desde sua chegada aqui, passando por sua adaptação ao modo de vida de uma sociedade ocidental - bem diferente da japonesa! - e a sua evolução até a completa integração nos dias de hoje. Sua sede está localizada em São Paulo, Capital, na Liberdade, bairro símbolo dos imigrantes no País.

1. Currículo Lattes. Disponível em: <http://lattes. cnpq.br/073875907098 5040>. 
Dentre as comemorações do Centenário da Imigração Japonesa no Brasil, ocorridas em junho de 2008, um dos trabalhos apresentados para a comunidade, e de grande importância para a memória da origem dos imigrantes, foi o lançamento do banco de dados com os nomes, locais de origem e de destino de cerca de 220 mil imigrantes japoneses. Com registros entre 1908 e 1973, os livros foram confeccionados pelas companhias de imigração e feitos com papel washi, de arroz, e todos os escritos redigidos em ideogramas japoneses. Os registros ficaram sob a guarda do museu e os dados foram transcritos por 126 voluntários, sob coordenação da Comissão de Registro Histórico da Imigração Japonesa no Brasil - Ashiato, do japonês "pegadas" ou "rastros", da Associação para Comemoração do Centenário da Imigração Japonesa no Brasil.

Na transcrição dos caracteres kanji para o alfabeto ocidental, famílias inteiras de imigrantes se uniram e participaram dos trabalhos; e tornou-se um desafio encontrar voluntários que soubessem interpretar os ideogramas arcaicos, já em desuso até mesmo no Japão. A participação das pessoas mais idosas foi decisiva. Outra dificuldade foi selecionar pessoas que digitassem no computador todos esses ideogramas, tanto os arcaicos quanto os atuais, uma vez que os mais velhos desconhecem a informática e os jovens, o japonês. Mas, em exatos três anos, quase toda a digitalização foi concluída e, até o momento, foram digitados dados de 322 livros de registros que estavam no Museu Histórico da Imigração Japonesa no Brasil e que serão doados de volta para o Museu e também para o Memorial do Imigrante, com o qual foi firmado um convênio para troca de informações.

\section{O MHIJB}

Atualmente, o MHIJB soma $1.592 \mathrm{~m}^{2}$ de área expositiva, dividida em três pavimentos: 7ㅇ, 8o e 9o andares, localizados no Edifício Bunkyo, em pleno bairro da Liberdade.

Os dois primeiros andares foram construídos em 1978 e reúnem documentos e objetos que abrangem desde a assinatura do Tratado de Amizade Brasil/Japão (1895), a chegada dos primeiros imigrantes (1908), os núcleos coloniais (a partir de 1913), até a policultura.

O $9^{\circ}$ andar, inaugurado em novembro de 2000, enfoca os 50 anos pósguerra. Nele estão retratadas as mudanças da comunidade nikkei, a vinda das empresas japonesas, bem como a contribuição dos nipo-brasileiros para a sociedade brasileira, ao atuarem em diversas áreas, desde produção agrícola, até comerciais, industriais, acadêmicas, jurídicas, militares, políticas, artísticas e de prestação de serviços.

Em outro piso ( $3^{\circ}$ andar) estão localizados a biblioteca e o acervo, que somam mais de 5 mil objetos, 28 mil documentos escritos (entre diários, livros, jornais, revistas) e cerca de 10 mil fotos relacionadas aos imigrantes japoneses. 


\section{A CHEGADA DOS IMIGRANTES}

Enfocando a trajetória dos imigrantes japoneses em ordem cronológica, o MHIJB abre o espaço expositivo, no 7o andar, com a documentação sobre o Tratado de Amizade, Comércio e Navegação entre o Brasil e Japão, assinado em 1895. Em seguida, apresenta uma galeria de destacados personagens anteriores à chegada da primeira leva de imigrantes japoneses em 1908.

A primeira vitrina desse andar enfoca a chegada no Brasil, reunindo réplicas dos navios Kasato Maru e Brasil Maru, e fotos de outros navios que também fizeram a mesma rota. Cenas da partida no Japão, a longa viagem, o desembarque em Santos e a chegada à Hospedaria dos Imigrantes em São Paulo são exibidas em fotografias e vídeo. Entre os documentos, cartas de encorajamento das autoridades, contratos de trabalho, passaportes, jornais editados a bordo do navio, relatório de viagem e manual para o aprendizado do português.

Em seguida, retrata a vida nas fazendas de café, representada por instrumentos de trabalho, utensílios domésticos, caderneta de despesas, entre outros documentos.

Para contar a trajetória dos japoneses no Brasil antes da Segunda Guerra Mundial, também foi montada a réplica de uma cabana que fora habitada por aqueles que se embrenhavam nas zonas de mata virgem para fazer as primeiras plantações. Ao lado da cabana, uma coleção de animais empalhados que habitavam nessas frentes de expansão agrícola.

Na seqüência, a exposição trata da formação dos núcleos coloniais de imigrantes japoneses, focalizando a preocupação com a manutenção da tradição cultural (criação de escolas, por exemplo), e também os esforços de adaptação ao novo ambiente. Assim, por exemplo, alguns utensílios domésticos e de trabalho foram copiados do modelo japonês ou, ainda, plantas silvestres adotadas para suprir a falta de verduras, que era um dos itens do hábito alimentar na terra natal.

Em seguida, a exibição ressalta o lazer e as atividades sociais nesses núcleos, através da prática esportiva (sumô, judô, beisebol, quendô, tênis, atletismo etc.) e eventos como o undôkai (competição poliesportiva), bailados e representação teatral. Destacam-se ainda os jogos de gô e shogui, os instrumentos musicais trazidos do Japão e até uma vitrola para discos de 78 rotações, com a qual costumavam ouvir as músicas japonesas para distrair a saudade.

No 7o andar também estão reunidos objetos referentes à produção hortifrutigranjeira, bem como de outros produtos agrícolas, com destaque para o cultivo de juta e pimenta-do-reino, desenvolvido pelos japoneses na região do Amazonas.

\section{CONTRIBUIÇÕES E DIFICULDADES: A CIDADE E A GUERRA}

Ainda neste andar, há a exposição de alguns dos produtos agrícolas introduzidos ou cultivados pelos imigrantes, com o propósito de mostrar a contribuição deles no setor agrícola. Aborda ainda as primeiras atividades dos japoneses na zona urbana, incluindo o comércio e as finanças. 


$$
\text { comunicação \& educação • Ano XIII • Número } 3 \text { • set/dez } 2008
$$

Também são destacadas as dificuldades enfrentadas pelos imigrantes japoneses durante a Segunda Guerra, quando o destino colocou os dois países em blocos opostos: proibição ao ensino e uso da língua estrangeira, com o conseqüente fechamento de jornais de língua japonesa; restrições às reuniões e viagens para outras cidades e o congelamento dos bens etc. Com o fim da guerra, a comunidade nipo-brasileira passou a viver outro drama decorrente do conflito, agora interno, motivado pela descrença e dúvida de alguns membros sobre a notícia da derrota japonesa. Os momentos difíceis foram superados com determinação e paciência, tendo o Brasil a chance de conhecer a enorme contribuição que a cultura japonesa viria oferecer ao projeto de unidade nacional.

\section{PÓS-GUERRA: AS NOVAS CONDIÇÕES DE VIDA}

Construído em 1997, o 9o andar abriga os temas relativos aos 50 anos do pós-guerra. Em cada lado da sala estão expostos painéis que utilizam diferentes linguagens para retratar cenas e personagens da trajetória japonesa no Brasil. Do lado direito há duas telas de 2,16 metros de altura, sendo que uma tem 7,3 metros de comprimento e outra, 7,80 metros. São cenas dos primeiros tempos da imigração, pintadas a óleo pelo artista plástico japonês Seiji Togo, em 1978, que, comovido pela história da saga dos imigrantes japoneses no Brasil, decidiu pintar tais cenas, falecendo antes mesmo de sua inauguração. No lado oposto estão 14 painéis fotográficos, em preto e branco, com 3 metros de altura por 1,5 metro de largura, registrando os 50 anos do pós-guerra.

Os objetos e documentos estão divididos em três temas básicos: 1) O alvorecer das novas relações bilaterais; 2) Mudanças na comunidade nikkei e 3) O desenvolvimento de uma nova era.

Esses temas englobam desde o reatamento das relações diplomáticas entre o Brasil e o Japão em 1952, até os dias atuais, com a intensa participação dos nipo-brasileiros em diferentes atividades do País e o processo decasségui (trabalhadores nikkeis no Japão).

Documentos, fotos e objetos também registram a chegada dos imigrantes do pós-guerra (agricultores, sericicultores e técnicos industriais), a intensificação do processo de urbanização da comunidade nipo-brasileira, a instalação das primeiras empresas japonesas no Brasil e a participação do capital japonês nos grandes projetos nacionais (exploração de minério, produção de papel e exploração agrícola do Cerrado).

O 9o andar possui, ainda, uma instalação multimídia, permitindo que os visitantes assistam a filmes contendo informações complementares sobre o período pós-guerra.

\section{TRAJETÓRIA DOS IMIGRANTES}

O primeiro navio vindo do Japão, Kasato Maru, chegou ao Brasil em 18 de junho de 1908, com 781 passageiros. Vieram contratados para trabalhar nas fazendas de café do interior do Estado de São Paulo. 


\section{O Museu Histórico da Imigração Japonesa no Brasil • Shozo Motoyama}

De 1908 até 1941 (às vésperas da eclosão da Segunda Guerra), emigraram para o Brasil cerca de 188 mil imigrantes-agricultores. Houve uma interrupção durante a guerra, e reiniciou-se em 1953, totalizando cerca de 50 mil imigrantes que chegaram após a guerra.

A vinda dos imigrantes ao Brasil foi resultado de uma conjugação de dificuldades e interesses de ambos os países - no Brasil, especificamente os fazendeiros de café, enfrentavam problemas com a mão-de-obra, desde que houve a libertação dos escravos negros e a suspensão da imigração européia. O Japão enfrentava uma das piores crises de sua história, marcada não somente por problemas econômico-financeiros, mas também por desemprego e excedente populacional.

Os imigrantes da primeira fase (até 1941) chegaram ao Brasil dispostos a trabalhar de 3 a 5 anos e economizar para retornar ao Japão. Poucos deles conseguiram atingir esse objetivo.

Depois de cumprir os dois ou três anos do contrato nas fazendas de café, a maioria deles não tinha condições de voltar ao país de origem e saiu para tentar a vida independente como agricultores, principalmente na zona oeste do Estado de São Paulo. Plantaram arroz, café, algodão, verduras, frutas, entre outros produtos.

Foi exatamente no pré-guerra que os imigrantes japoneses começaram a ser conhecidos como agricultores. Em 1912, 92,6\% deles dedicavam-se ao cultivo do café. Em 1942, essa porcentagem muda - apenas 24,3\% cultivavam café, aumentando o cultivo do algodão $(39,2 \%)$ e das culturas chamadas suburbanas $(19,9 \%)$, como verduras, legumes, frutas e avicultura. Logo após o final da Segunda Guerra Mundial, intensifica-se o movimento de êxodo rural entre os imigrantes - deixam a zona rural para morar e trabalhar na cidade (na capital ou no interior). As famílias investem em pequenos comércios (lavanderias, mercearias, feiras, cabeleireiros, oficinas mecânicas etc.) e concentram-se na educação dos filhos. Outras famílias decidem morar na zona suburbana (dedicando-se às atividades hortifrutigranjeiras), devido à proximidade de boas escolas para os filhos nas cidades maiores. Em 1952, 34,1\% dos imigrantes japoneses estavam voltados para as atividades hortifrutigranjeiras, enquanto os plantadores de café japoneses tinham baixado para 27,5\%, e de algodão, para 20,5\%. É interessante observar que dados de 1988 indicam que $80 \%$ dos nipobrasileiros estavam residindo na zona urbana, mas, ainda assim, continuavam com a fama de agricultores.

Calcula-se que cerca de 1,4 milhão de brasileiros sejam descendentes de japoneses, e perto de $80 \%$ deles residam no Estado de São Paulo, e, aproximadamente 360 mil, na cidade de São Paulo.

Estima-se que quase 300 mil brasileiros descendentes de japoneses estejam trabalhando no Japão. Trata-se do movimento chamado decasségui (literalmente, trabalhador temporário), iniciado por volta de 1985. Atingiu seu ponto alto em 1991 (96,3 mil, durante esse ano, foram ao Japão), com a mudança da legislação do Japão e a crise econômico-financeira brasileira. 
comunicação \& educação • Ano XIII • Número 3 • set/dez 2008

\section{Serviço}

\section{Museu Histórico da Imigração Japonesa no Brasil}

Rua São Joaquim, 381 - 3o andar/sala 39. Liberdade - São Paulo-SP

CEP 01508-900 - Tel/fax: (11) 3209-9565/ 3208-1755

E-mail: museu@bunkyo.org.br

Exposição: De terça a domingo: das $13 \mathrm{~h} 30$ às $17 \mathrm{~h} 30$. Ingressos: $\mathbf{R} \$ 5,00$ (adultos), $\mathrm{R} \$ 2,50$ (estudantes com carteirinha), $\mathrm{R} \$ 1,00$ (crianças de 6 a 11 anos). Entrada franca: menores de 5 anos e idosos acima de 65 anos.

Biblioteca*/Escritório: De segunda a sexta-feira: das $8 \mathrm{~h} 30$ às $12 \mathrm{~h} 00$ e das $13 \mathrm{~h} 30$ às $18 \mathrm{~h} 00$ (segunda-feira, a partir das 9h00). Sábados: das $13 \mathrm{~h} 30$ às $18 \mathrm{~h} 00$. Tel./Fax: (11) 3209-5465 ou 3208-1755 (ramal 117).

E-mail: museu@bunkyo.org.br

(*Biblioteca apenas para consulta local.) 